ISSN: 0213-2079

DOI: http://dx.doi.org/10.14201/shhmo201436101120

\title{
LEPANTO: ANTES Y DESPUÉS. LA REPÚBLICA, LA SUBLIME PUERTA Y LA MONARQUÍA CATÓLICA
}

\section{Lepanto, before and after: Between the Republic and the Sublime Porte}

Özlem KUMRULAR

Universidad de Bahçeşehir, Estambul

Correo-e: ozlem.kumrular@bahcesehir.edu.tr

RESUMEN: La caída de Chipre en manos de los otomanos, seguida de la batalla de Lepanto, era el primer motivo de las relaciones diplomáticas heladas y causó la ruptura de la paz tradicional entre Venecia y Constantinopla. Sin embargo, hay una diferencia notable entre la conceptualización histórica y política de estos dos importantes episodios. El estado otomano no interpretó esta catástrofe como lo hizo la República. Como se puede atestiguar de la diplomacia bilateral mantenida por los dos estados, ni la pérdida de Chipre, ni la batalla de Lepanto, que creaba nuevos mitos, podía cambiar la política oriental de la Serenísima. El caso no era diferente para la Sublime Puerta. El motivo de este trabajo es analizar las políticas de posguerra de los dos estados y el cambio notable en la polarización política en Europa en el ámbito de la rivalidad entre los Otomanos y los Habsburgo.

Palabras clave: Lepanto; Venecia; Imperio Otomano; Chipre; Constantinopla.

ABSTRACT: The loss of Cyprus to the Ottoman Turks, hand in hand with the battle of Lepanto was the major reason of a period of frozen politics and caused the breaking of the traditional peace between Venice and Constantinople. Yet there is a notable difference between the historical and political conseptualization of these two major episodes. The Ottoman state didn't interpret this catastrophe as the Republic did. As, it could be 
seen from the bilateral diplomacy carried out by both states, neither the loss of Cyprus, nor the myth-creating Lepanto could change the classical oriental policy of the Serenissima. The case was not different for the Sublime Porte. The aim of this paper is to analyse the post-war politics of these two states and the noteable change in the political polarization in Europe in the milieu of the Ottoman-Hapsburg rivalry.

Key words: Lepanto; Venice; Ottoman Empire; Cyprus; Constantinople.

Cuando la capilla SS. Giovanni e Paolo fue destruida por el incendio en 1867, el cuadro de la batalla hecho por Iacopo Tintoretto y su hijo Domenico también perecieron. La misma desgracia cayó sobre otro cuadro que salió del pincel de Iacopo Tintoretto en el Palacio ducal en Venecia ${ }^{1}$. Del mismo modo, la enorme palmera que se encontraba en los jardines de Colonna desde hacía tres siglos y que fue plantada para conmemorar la batalla de Lepanto desapareció ${ }^{2}$. La desaparición de los objetos de arte que se crearon para inmortalizar la victoria contra los turcos parecen haber sufrido una maldición paralela con la reconstrucción de las fuerzas navales turcas. Sin duda, si las noticias de todos estos objetos de arte destruidos por los catástrofes naturales hubieran llegado a los oídos de los turcos, infaliblemente lo habrían atribuido a Dios. Cuando las representaciones de la gloriosa batalla se perdían una tras otra, las atarazanas en la capital otomana se convertían en el centro de trabajo acelerado.

No sería exagerado proclamar que Lepanto fue inmortalizado casi en todas las ramas del arte y este proceso de inmortalización continuó hasta finales del siglo XIX. Iain Fenlon, en su famoso artículo «Lepanto and the Arts of Celebration» hace una pregunta retórica cuya respuesta ilumina los confines de la esfera iconográfica de la batalla. "¿Qué tienen en común los elementos? Una marca de brandy español, una estación de metro en Roma y un sello hecho por Lesotho en que Mickey Mouse está presentado disfrazado de don Juan de Austria. La respuesta: todos conmemoran la batalla de Lepanto» ${ }^{3}$.

La toma de Chipre por los turcos, después agravada por la batalla de Lepanto, era el centro de interés de la política gélida y paralizada de este periodo y causó la ruptura de la paz tradicional entre Venecia y el Imperio Otomano. Sin embargo, existe una diferencia notable entre la conceptualización de estos dos episodios

1. Freiherr von Pastor, L.: History of the Popes, ed. Kerr, R. F. vol. XVIII. Londres, 1952, p. 447.

2. Idem, p. 448.

3. FENLON, I.: «Lepanto and the arts of celebration in Renaissance Venice», Proceedings of the British Academy, 73, 1987, pp. 201-36. 
predominantes. El estado otomano no interpretó la catástrofe como lo hizo la República. Como se puede ver en la diplomacia bilateral realizada por los estados, ni Chipre, ni el mítico Lepanto pudo cambiar la política oriental de la Serenísima. Y el caso no era diferente en el contexto otomano.

Eran los turcos quienes rompieron la paz, como la Señoría abiertamente comentó en los despachos que envió a otras cortes. Comentaron que los turcos violaron la paz sin ninguna excusa válida. Eso sí, sin duda. La hostilidad creció de repente pero no inesperadamente por el ataque turco a Chipre, por cuya posesión la República pagaba 8.000 ducados anualmente a la Sublime Puerta. Entre otros rumores, se decía que un judío de origen portugués, José Miquez, -llamado Josef Nassi por los otomanos-, era el provocador y promotor de la guerra. Este hombre, impulsado por sus ambiciones de gobernar esta isla después de la conquista organizada, animó al Sultán para capturar este territorio geoestrategicamente importante. No faltaron los rumores concernientes al amor y la afición de Selim II por el vino chipriota. Fuera lo que fuera el motivo general del ataque, la realidad innegable era que la guerra de Chipre afectó negativamente el comercio veneciano y el número de los comerciantes empezó a caer de una manera considerable.

A principios del año 1570, la República era consciente de lo que ocurriría y no perdió tiempo ni oportunidad para buscar aliados potenciales para evitar la amenaza otomana. Una carta con fecha 3 de mayo de 1570, despachada por la Signoria al Patriarca griego de Constantinopla no solo revela la tensión de los venecianos, sino también refleja los aspectos generales de su política futura. «Deve essere molto ben noto a Vostra Serenita Reverendissima», decían los venecianos

con quanta impieta il turco ne habbia mossa la guerra, rompendo senza alcuna causa quella pace, che poco tempo prima havea, con solennissimo giuramento, confirmata, operatione, che come e stata contra ogni ragione, et divina et human cosi e da credere, che sia stata permessa dal Signor Dio, per dar occasione alla Christianita de reprime l'audacia di questo commune inimico, il quale, non contento di tenir in servitu gran parte della Chiesa Greca, aspira ad occupar anco il regno nostro de Cypro, et altre isole nostre di Levante, ove li Greci sotto la protettione nostra liberamente possono servire al Salvator nostro Jesu Christo, secondo i riti et consuetudini antique della Chiesa Greca, come fanno anco in essa essercitano li riti et consuetudini loro... ${ }^{4}$.

El despacho es verdaderamente interesante y notable en diferentes aspectos. Especialmente por su perspectiva religiosa. El término «Salvator nostro Jesu Christo», en lugar de las referencias clásicas a Jesús, son la evocación de su esencia divina, muestra la actitud clásica veneciana. Una yuxtaposición de otros despachos

4. Lamansky, V.: Secrets d'etat de venise: Documents extraits notices et etudes, Nueva York, 1968, vol. I., p. 1078. 
enviados a los monarcas católicos con este demuestra abiertamente las diferencias obvias. En segundo lugar, un término como «l'audacia di questo commune inimico», uno de los más repetitivos términos de los despachos del siglo XV, reservado para el turco, es impactante cuando sale de la pluma de los venecianos. Venecia, que siempre había sido muy prudente con su terminología política y diplomática, ahora se desvía de su código diplomático clásico. El resto de la carta muestra las otras preocupaciones y perturbaciones de la Serenissima en las vísperas de la guerra:

habbiamo voluto pregar Vostra Signoria Reverendissima, che sia contenta a laude et gloria del Serenissimo nome di Jesu Christo, a beneficio universale della Christianita, et particolare della Chiesa Greca, dar quei secretissimi ordini, che li parera, accioche quando la nostra armata si appresentara alle marine sopradette della Morea et altre, si scopra il valor Greco a favor di essa armata contro Turchi; perche noi promettemo alla Signoria Reverendissima in fede di vero et christiano Principe, siccome siamo stati richiesti dal sopradetto malaxo, che noi conserveremo et faremo conservar a tutti questi Greci, che veniranno sotto la nostra protettione in qual si voglia modo, tutti li riti et consuetudini.

La carta muestra las coordenadas geográficas de la guerra esperada y anticipada. Sin embargo, un detalle más chocante es el de la exhortación de los griegos y el uso de un tono heroico. Las siguientes palabras sacan a la luz la posibilidad de otro aliado: «el príncipe de Moscovia»:

Pero pregamo la Signoria Vostra Reverendissima, che con quei mezi, che li parera, facci officio con il prefato Serenissimo Imperator di Moscovia, che con le sue grandissime forçe, si mova contra il Turco, per non perder cosi grande occasione de vendicar se di tante injurie li ha fatta la casa Otthomana ${ }^{5}$.

El mismo día, los venecianos enviaron una carta al emperador de Moscovia, rogándole que resistiera "alle forçe di questo tiranno» ${ }^{6}$ elogiándole con palabras animadores y laudatorias:

Et sopra tutti la Maestra Vostra, la qual in ogni occasione ha fatto sempre grandissimi danni a Turchi con inmortal gloria del suo altissimo animo et col grandissimo valor delli soi amplissimi regni et stati, si fara sentir a danno et ruina di questi infideli, et che non vorra passar questa occasione di far felicissimi progressi, dovendo esser il Turco occupato dalla parte de mar con l'armata, et anco con l'essercito da terra, volendo tentar l'impresa de Cypro.

5. Ibidem.

6. Ibidem.

7. Ibidem. 
Este parecía ser el punto de inflexión de las relaciones turco-venecianas. Esta interesante deviación política también incluyó a los griegos ortodoxos y los moscovitas. Eran tiempos de fragilidad y tensión. El ambiente antes de la guerra era más tenso que nunca, especialmente después de la guerra de las Alpujarras. La guerra de Chipre no era algo totalmente inesperado para los venecianos. Obviamente esperaban el estallido de guerra.

La reacción y la actitud del bailo Marcantonio Barbaro parecían apoyar a este hecho: No perdió la calma y su capacidad de negociar en las peores condiciones: Las galeras de Florencia y Malta estaban involucradas en operaciones ofensivas del corso contra los turcos. La corte otomana sospechó que los venecianos daban apoyo logístico a las actividades antiturcas.

En 1569, Marcantonio Barbaro escribió estas palabras en la carta que remitió al Dux Loredano:

Se puede decir que el negociar es similar a jugar con una bola de vidrio; es necesario sostenarla con destreza siempre en el aire, no dejándola caerse en tierra, ni tirarla con furia porque se rompería, sino tomarla diestramente y después, con oportunidad, volver a enviarla vivamente ${ }^{8}$.

Marcantonio Barbaro vivió en Constantinopla desde 1568 hasta 1574, exactamente durante la tensión causada por la guerra de Chipre y la batalla de Lepanto. No fue muy afortunado en sus tesis diplomáticas. Su teoría del vidrio frágil desapareció en el entorno político otomano. La bola se rompió en las manos de los otomanos: fue encarcelado y tuvo que sufrir por la actitud política del Senado. Al menos, tuvo tanta suerte para no estar encarcelado en la «torre negra» de la costa europea del Bósforo. En su lugar, tuvo que sufrir este periodo en su propia casa bajo el control de unos «çavuş» ${ }^{9}$ Incluso bajo estas condiciones difíciles, consiguió trasmitir varias copias de cartas a la República. Entre la gente que le prestó su ayuda para obtener y trasmitir noticias importantes, estaba el médico judío del Sultán, Salomón Ben Nathan Askenasi.

No fue solo Barbaro, sino también los mercaderes venecianos quienes fueron detenidos. Pero, afortunadamente las condiciones bajo las cuales estos fueron encarcelados no eran particularmente difíciles. Encontraron un refugio en la casa del bailo Barbaro. Cuando las noticias horripilantes de la guerra de Chipre llegaron a los oídos de los venecianos, estos decidieron actuar del mismo modo contra

8. SOLA, E.: Los que van y vienen: Información y fronteras en el Mediterráneo del siglo XVI. Alcalá de Henares, 2005 , p. 212. «Negociar es similar a jugar con una bola de vidrio; es necesario sostenerla con destreza siempre en el aire, no dejándola caerse en tierra, ni tirarla con furia porque se rompería, sino tomarla diestramente y después, con oportunidad, volver a enviarla vivamente».

9. Bertelè, T.: Il palazzo degli ambasciatori de Venezia a Costantinapoli e le sue antiche memorie. Bolonia, 1932, p. 108. 
los turcos que entonces se hallaban en Venecia. Se creía que, este antagonismo podría dar lugar a la rendición de la Sublime Puerta y facilitar la recuperación de los venecianos detenidos ${ }^{10}$.

La captura y la reclusión del çavuş otomano Mahmut Bey en su camino hacia la corte francesa con otros turcos y judíos que fueron acusados por los venecianos de haber provocado esta guerra, en el Castello de San Felice hasta el final de la guerra era un ejemplo de esta actitud hostil. La cifra de estos turcos debía ser considerablemente alta, así que en 1571 Mehmet Paşa propuso al Senado el intercambio de los prisioneros turcos y venecianos con todas sus propiedades capturadas.

Del mismo modo, el Grand Visir Mehmet Sokullu mantuvo un contacto con el bailo veneciano por la cuestión de los prisioneros turcos en Venecia. Luego, en mayo se les prometió el reinicio de sus operaciones comerciales en Rialto, probablemente a cambio de una libertad similar a la que se prometía a los mercaderes venecianos en la capital otomana.

Durante la guerra de Chipre, se vio la represión de los agentes extranjeros. Barbaro tuvo muchos problemas para comunicarse con sus hombres. Algunos de estos fueron descubiertos y ejecutados. Paolo Biscotto era uno de los ejemplos más llamativos. Le pillaron con las cartas que llevaba a Rabi Salamon, el médico del Sultán, y con uno de sus contactos nuevos. Esta figura también jugó un papel importante en la introducción de los españoles en este mundo de información ${ }^{11}$.

El Diario di prigionia del maestro di casa del bailo Marcantonio Barbaro es uno de los documentos más vivos que pinta el retrato de todas las caras del caos que reinaba en Constantinopla antes y después de Lepanto. El diario se atribuye al maestro di casa, cuyo nombre nos es desconocido. En su diario el maestro di casa apunta los detalles intrigantes de la tensión que se vivía en la capital otomana desde el intercambio de los mercaderes que se negociaba hasta la detención del dragoman Ludovico Marucini. En una ciudad donde la tensión dominaba el ambiente político y social, una de las cosas llamativas era el cerramiento de las ventanas de la casa del baile. Un día venían a cerrarlas, otro día para abrirlas. El estado de ánimo de un prisionero cambiaba por la apertura o cierre de las ventanas y esto se reflejaba en las líneas del diario que nos dejó:

Alli 2 luglio fu aperta una finestra nella camera del maestro di casa, quella che guardava la porta da dietro; et questo fu con grandissima allegrezza di tutta la casa che pativa assai per non haver visto alcuna ${ }^{12}$.

10. Paruta, P.: Historia dell Guerra di Cipro. Venetia, 1615, p. 35, citado por Preto, P.: Venezia e i turchi. Florencia, 1975, p. 128.

11. SOLA, E.: Los que van y vienen: Información y fronteras en el Mediterráneo del siglo XVI, p. 216.

12. Pia Pedani-Fabris, M. (ed.): Relazioni di ambasciatori veneti al Senato, vol. XIV. Padua, 1996, p. 164. 
A dì 10 ditto (Luglio) fue aperta una finestra di la sala, et 2 in camera dil signor bailo.

Alli 14 ditto fu riserato la finestra del maestro di casa, et così come si hebbe grandissima allegrezza quando la fu aperta, cosi si hebbe grandissimo dispiacere a serrarla; pacientia, piace così a Iddio ${ }^{13}$.

El escritor anónimo del diario nos da una descripción horripilante de las desgracias que sucedieron al frer italiano, susodicho Paulo Biscotto:

Alli 28 ditto (Aprile) fu fatta la sententia di fra Paulo Biscotto, che fusse impalato per mezzo la chiesa di Santo Francesco per esser lui di tal ordine; et così il detto giorno fu menato per avanti della casa del clarissimo bailo con il palo in spalla, et menatolo a Santo Francesco fu di longo impalato. Et il giorno dietro li fu tirato, mentre era sul palo, alcune frerzate da alcuni asapi, et così stete. Vi era presente il nostro capellano che si dubita di lui; ma fu misso in galera; si riscatò con 2000 ducati d'oro ${ }^{14}$.

No era sorprendente que los italianos fuesen «cabeza del turco» de la venganza otomana.

Ni era el único ejemplo. Del mismo modo, la flota de la Liga Santa navegaba hacia Corfú y le llegaron las noticias trágicas del final horroroso de Bragadino: ¡Los turcos despellejaron al desafortunado hombre, rellenaron su piel, le vistieron con el uniforme veneciano y le arrastraron por la ciudad! ${ }^{15}$.

El 24 de octubre, el «maestro di casa» registra la llegada de las malas noticias para los otomanos: La derrota en el golfo de Lepanto «A di 24 ditto venne nuova come l'armata christiana fece giornata con quella dil Turco nel porto di Lepanto et come quella dil turco era tutta sta fracassata con grandissima perdita», dice ${ }^{16}$.

A dì 7 di ditto (novembre) Arapapaginat con 17 galere et 3 maone, per la qual venuta fu scaricata tanta artegliaria et fatti tanti trionfi et feste che fu una cosa grandissima, andando più oltre su et giù per il canale di poi andò all'Arsenal, là dove sbarcarano 850 schiavi di quelli di Famagosta, homini tutti grandissimi et grossissimi furono messi tutti nel bagno del Signor. Condusse pur la pelle del Bragadin, qual era capitano di Famagosta, piena di paia, la qual fu mostrata al popul azziò per dargli ristoro. Dicono que Mustaffa bassà li fece scorticar mezo et poi li fece lasar così atacato fno a mezo di per dargli più tanto più pena; et esso signor Bragadin stete sempre constante ringraziando la Divina Maestà sempre d»ogni cosa, non si perdendo mai d'animo ${ }^{17}$.

13. Idem, p. 164.

14. Idem, p. 162.

15. Freiherr von Pastor, L.: History of the Popes. Edición de R. F. Kerr, vol. XVIII, p. 418.

16. Relazioni di ambasciatori veneti al Senato, vol. XIV, p. 166.

17. Idem, p. 166. 
El 17 de octubre, El ángel trajo buenas noticias a Venecia. La llegada de Onofre Justiniano con las nuevas gloriosas causaron una euforia en Venecia. Dux, Senato, la nobleza y el público salieron a la plaza para celebrar este suceso mítico. Las nuevas llegaron a la corte española con retraso. Era el embajador español quien llevó estas noticias al rey. Las noticias fueron recibidas con alegría, pero no tan pomposamente como en Italia. Felipe II recibió las noticias en las vísperas de la fiesta de Todos los Santos en el Escorial. Estaba tan sereno como estaba su padre al recibir las «nuevas» de la victoria de Pavia ${ }^{18}$. No dio ninguna muestra de asombro. Por otro lado, la alegría en Roma naturalmente no era inferior. El Papa, que había profetizado la victoria según decían, se echó a llorar. Las festividades y celebraciones duraron semanas. A pesar de todas las hostilidades, la reina Elizabeth despachó una declaración a Felipe II incitándole y exhortándole para que siguiera con su guerra anti turca ${ }^{19}$. Desde las canciones griegas populares compuesta por los pescadores griegos hasta las escenas pintadas en las cúpulas de las iglesias, desde los cuadros que salieron de las manos de los japoneses en la otra parte de la tierra gracias a los misioneros jesuitas hasta versos larguísimos escritos por los italianos y españoles, se crearon un número asombroso de obras de arte y literatura.

El día 8 de noviembre de 1571, Consiglio dei X registró estas palabras en el informe de las decisiones del suceso importante:

Se ha meritato mai alcun egregio fatto, occorso con honor della Repubblica nostra, d'esser representato et tenuto vivo agli occhi et alla memoria delli posteri, lo merita sopra ogni altro questo della Vittoria cosi segnalata et illustre, contro l'armata turchesca $^{20}$.

El despacho del Papa enviado a Shah Tahmasb invitándole a un ataque inmediato contra los turcos no dio ningún fruto. En este sentido, no solo la invitación sino también el resultado nos recuerda el caso de Carlos V en busca de una ayuda en el Oriente contra el turco. Ni sus diplomáticos, ni los del Papa consiguieron encontrar una alianza prometedora en esta geografía, aunque la buscaron con no poca esperanza ${ }^{21}$. El Papa, aparte de los despachos que emitió a los monarcas cristianos, envió cartas a todos los aliados potenciales: al rey de Portugal, al rey de Etiopia, al sheik Mutahat, príncipe de Arabia Félix ${ }^{22}$. Además, después de Lepanto «Exhortó el vencedor de Lepanto para glorificar a Dios, quien a pesar de nuestros

18. Rosell, C.: Historia del combate naval de Lepanto, Madrid, 1853, p. 124.

19. ARI, B.: «Las últimas fases de la lucha por el dominio del Mediterráneo entre dos superpotencias; el Imperio Otomano y la Monarquía Hispana» en Martín Asuero, P.; YaycioĞLu, M. y Toledo, P. (eds.): Cervantes y el Mediterráneo Hispano-Otomano, Estambul, 2006, p. 118.

20. Pallucchini, A.: «Echi della battaglia di lepanto nella pittura Veneziana del '500». p. 279.

21. ARI, op. cit., p. 118.

22. FreIHERR VON PASTOR, op. cit., vol. XVIII, p. 427. 
pecados, había sido tan cortés y misericordioso» ${ }^{23}$. Ahora que se cumplió su sueño, empezó a pensar en el segundo paso: la liberación de Jerusalén y la conquista de Constantinopla. ¿ No eran unos sueños utópicos? Sí, lo eran.

Lepanto era un preludio a una serie de festividades para dar gracias a Dios en la ciudad de los canales. Sin embargo, había un puñado de gente que estaba sumamente preocupada y afligida por la llegada de las noticias de la derrota de la armada turca en las aguas de Lepanto: los mercaderes turcos. El pánico causado por la llegada de estas nuevas debería haber sido enorme. Deberían haber recibido las noticias con un miedo terrible y turbación; como las noticias del maltrato de las autoridades otomanas a los delegados y diplomáticos que fueron condenados al encarcelamiento, que no les era desconocido. Estaban atemorizados, pensando que alguna desgracia les vendría encima. Las horripilantes historias verdaderas de los que sufrieron en las torres de Estambul a manos de los guardianes les deberían haber llegado en olas de información. El miedo les llevó a una serie de preparaciones grotescas para evitar la ira del estado veneciano, entonces victorioso y que no tenía nada que temer. Los mercaderes turcos huyeron de Rialto y se encerraron en sus casas durante cuatro días por el miedo. Para evitar el castigo amargo y vejatorio de ser dilapidados por los niños, se cortaron los bigotes. ¿Qué podría ser más típico que un par de bigotes largos a la hora de hablar de apariencia física? Es algo que podemos interpretar y entender. Pero, lo que somos incapaces de interpretar son las otras reacciones raras e incomprensibles que estos mercaderes mostraron. Se dice que se tiraron al suelo, se pegaron el pecho y pellizcaron la cara y la carne. Parece que los venecianos usaron un poco de exageración a la hora describir este modo oriental de luto ${ }^{24}$.

El tiempo era el único remedio frente a la inquietud de estos mercaderes. 1573 fue el año en que su malestar llegó a su apogeo. En primer lugar, porque fue el año que se firmó el tratado de paz entre la Sublime Puerta y República. En segundo lugar, se propuso que para la seguridad de las mercancías tenía que haber un gueto como el de los judíos ${ }^{25}$.

Los sectores cristianos usaron esta oportunidad hasta el último momento. Una innumerable cantidad de cosas se escribieron sobre la batalla, casi en todos los géneros. El caso se aprovechó para hacer el cuadro grotesco de los soldados turcos. Una escena descrita por un tal Diedo, que participó en la batalla, merece ser citada aquí: después de describir la matanza y los horrores del ataque, nuestro autor sigue con la relación de lo que hicieron algunos turcos y afirma que

aquellos turcos que no pudieron escapar a la tierra, ni tirarse al agua (como hicieron algunos) lucharon con tanta obstinación que finalmente algunos se quedaron sin

23. Idem, p. 433.

24. Preto, P.: Venezia e i turchi. Florencia, 1975, p. 129.

25. Idem, p. 130. 
armas de defensa. Y en consecuencia, cogieron las naranjas y limones de los que una buena cantidad había a mano, e intentaron molestar a nuestros hombres con estas (frutas). Algunos de estos, por desprecio o para burlarse de ellos, se las tiraron a ellos. Esta forma de conflicto parece haber ocurrido en muchos lugares hacia el final de la guerra y era motivo de risa ${ }^{26}$.

Volviendo a Constantinopla después de la llegada de las noticias, deberíamos echar un vistazo a la carta con la fecha 30 de octubre de 1571 del bailo en esta capital dirigida al Senato:

Serenissimo Principe;

Se ben la vittoira cosi segnalata et grande si è hauta, e stata per quanto qui si ragiona non solamente la maggior che per il tempo passato sia mai successa, ma che nè anco potessero gli homeni desiderare, pur crederò che la principal consolatione di quel prudentissimo et serenisssimo dominio non sarà sopra il fatto seguito, con tutto che più felicemente non el potesse succeder, ma nel poter da esso venir in ferma cognitione che questa sia stata gratia et spetial voluntà del Signor Dio, et massime essendo la Serenità Vostra memore di tutte le principal attioni seguite dopo che si rupe la pace, so che lei più di ogni altro lo conoscerà, per questa consideratione adonque confesso non aver mai più sentito simil consolatione la qual tanto più si va conservando nell'intimo dell'animo mio, quanto che parmi che si possa sperar che la bontà et providentia divina vorà hormai solevar il grege et popolo suo, si come ogni devota supplicatione la si deve pregare, onde io mi confido che con qualla prudentia che concede il Signor Dio e quel Ecc.mo Senato, et con la intelligenta et cognitione che egli ha del stato di questo imperio et di questo luogo specialmente havera di già prese bone risolutioni, et saperà molto bene conoscer le occasioni, et io da mio canto mi forzarò con ogni mio poter di far intender alla Serenita Vosta quel più che sara possibile delle operationi et disegni di qua, accio che più fondatamente la possa regolar i giuditij soi, ma fin hora non posso venir a particolar alcuno, si perchè il Signor si ritrova in Andrinopoli con... ${ }^{27}$.

Barbaro era el único que tuvo que negociar con la Sublime Puerta para lograr una paz ventajosa después de todos estos meses de reclusión. Cinco meses de negociaciones secretas dieron sus frutos el 7 de marzo de 1573 y la deseada paz se concluyó ${ }^{28}$.

26. «Battaglia di Lepanto descritta da Gerolamo Diedo», Biblioteca Rara. Misc. Vol I, p. 169.

27. BERTELÈ, op. cit., p. 112

28. El tratado fue traído a Venecia por el hijo del bailo, Francesco. Después de ser aceptado por el Senado, fue confirmado por el embajador Andrea Badoer, quien acompañó al nuevo bailo Antonio Tiepolo hasta Constantinopla. Tommaso Bertelè comenta: «Esempi di dignità e di coraggio diedero anche in tale occasione i diplomatici veneziani, sia nel pretender che, in occasione del ricevimento da parte del sultano. Fosse loro accordato il consueto solenne banchetto, che sà voleva negare per abbassare il prestigio della repubblica (Tanto che, nonostante pressioni e minacce, si rifiutaron perfino 
Los otomanos comentaron que la derrota era la cosa más desastrosa que ocurrió en la Sublime Puerta. Por ejemplo, el historiador Ali confirmó que «la historia no registraba una catástrofe de esta naturaleza desde la creación del mundo y los tiempos del Arca de Noé» ${ }^{29}$. Sin embargo, los otomanos mostraron una serenidad admirable en los asuntos extranjeros. Como no solían mostrar ninguna arrogancia después de las grandes victorias, esta vez también mantuvieron su tranquilidad y serenidad. El estado otomano se encontraba en una tranquilidad sorprendente y estaba lejos de estar asustado. Especialmente después de la caída de Famagusta. En un informe fechado 28 de octubre, enviado a Pertev Baja, se comenta que «Una guerra puede conducir a la victoria o a la derrota ${ }^{30}$. Ello pertenece al designio del Todopoderoso ${ }^{31}$. Como se puede ver abiertamente, el modo fatalista de interpretar las victorias y derrotas no estaban en el monopolio de los cristianos. Todos los cronistas otomanos acaban diciendo que era el plan del Dios para advertir a los creyentes musulmanes por sus pecados.

He aquí la descripción de la entrada de la parte de la armada otomana que se pudo salvar de la batalla:

A 28 dezembrio venne in Costantinopoli Lugiali vice re d'Algier con il residuo dell'armata che restò dalla rotta datali dalli collegati, cioè dal papa, re Filippo et la Signoria di Venezia, et il detto Lugiali entrò nel porto di Costantinipoli con galere numero 26 et 9 palandarie, le quale galere et palandarie fecero una superbissima intrata scargando tanta artegliaria che parevano esser più di 200 , quali galere venendo tutte con un ordine abrazando tutto il canale da una banda et dall'altra facendo con la voce una allegrezza grandissima, et tutto fu fatto con arte per allegrare il populo, il qual concorse tutto alla marina et che in cima alle case il qual popolo la maggior parte piangeva et cridava dicendo ad alta voce «Amedet, Amedet», che vuol dire «O Dio mio, o Dio mio. Dove il mio marito, dove il mip padre, dove il mio fratello», et via discorrendo, sì che non si mancavano li pianti per tutto, ma quelli dell'armata si sfogavano li cridi con il lor rumore de l'artiglieria ${ }^{32}$.

di recarsi all'udienza stabilita dove già si trovava il sultano con alcune migliaia di persone), sia disponendosi il Badoer a lasciare Costantinopoli perchè i negoziati in corso con la Porta si trascinavano troppo a lungo senza risultati».

29. İNALCIK, H. «El imperio otomano y España en el Mediterráneo (1551-1571). Lepanto en los documentos otomanos», en MARTín Asuero, et. al., op. cit., p. 20.

30. Carta imperial del sultán.

31. İNALCIK, op. cit., p. 21.

32. Relazioni di ambasciatori veneti al Senato, vol. XIV, p, 167. «Y, como ya habréis, señores, oído decir que el Uchalí se salvó con toda su escuadra, vine yo a quedar cautivo en su poder, y solo fui el triste entre tantos alegres y el cautivo entre tantos libres; porque fueron quince mil cristianos los que aquel día alcanzaron la deseada libertad, que todos venían al remo en la turquesca armada», Cervantes, M. de: Don Quijote de la Mancha, I, cap. XXXIX. 
Mientras tanto aparecieron rumores proclamando que el Gran Turco había mandado «la decapitación de todos los embajadores de los príncipes cristianos» después de recibir las noticias de la pérdida de su escuadra en Lepanto ${ }^{33}$. Estos «avisos» que se guardan en el Archivo General de Simancas eran sin duda infundados. Pero de una cosa no cabía duda: que la Puerta empezó a seguir una política muy dura no solo contra los venecianos, sino contra todos los italianos y españoles que se encontraban en la capital. Los castigos usuales se convertían en unos auténticos suplicios. El anónimo «maestro di casa» del bailo Marcantonio Barbaro nos relata detalladamente lo que sufrió un fraile delante de la Iglesia de San Francesco en Pera. Sin duda, se trataba de una venganza general por la «batalla naval»:

Domenica alli 18 d'agosto 1572 fu giustiziato un frate di Sant'Agostino su la piazza di san Francesco che era di 26 in 28 anni, il quale era stato schiavo et si liberò et haveva trovato commodità di uscir dal paese del Turco ma voleva condurre seco uno putto cipriotto fatto turco, il quale putto voleva andare ma disse al suo patrone la cosa, il qual patrono fece subito prendere esso frate et essendo essaminato con tormenti confessò la cosa, la dove fu condannato al palo; et così passò dinanzi la nostra casa con gran numero di persone, ma il poverino era tanto afflitto che non poteva stare in piedi et non poteva portare il palo in spalla ma lo porta uno appresso lui. Gionto allo loco fu, non si sa chi, che donò 3 scudi al boia che lo apicò. Iddio habbia la sua anima. Due turchi di compassione aiutavano uno di qua l'altro di là il povero frate, il qual non poteva star in piedi tanto era consumato; morì con grandissima constantia, havendo prima fatta la sua oratione in genocchioni su la porta della giesa. Veramente la sua gran constantia fece meravigliar molti turchi ${ }^{34}$.

No sería ninguna exageración proclamar que era esta tranquilidad de los otomanos lo que les abrió el camino que llevó a un tratado muy beneficioso. Como los historiadores que trabajan en el tema afirman, parecía que eran los otomanos quienes habían ganado la batalla. La derrota de Lepanto era incomparable a ninguna otra en el contexto otomano: 100 galeras otomanas fueron capturadas por las fuerzas de la Liga Santa y otras 60 se hundieron. Los otomanos perdieron 18.000 hombres y 10.000 cayeron esclavos en manos de los cristianos. La cantidad de dinero y los objetos saqueados tampoco era poca: Don Juan de Austria capturó

33. Archivo General de Simancas, Estado, K.1525, 1572 Enero, Marzo.

34. Relazioni di ambasciatori veneti al Senato, vol. XIV, p. 171. La actitud severa y violenta de los turcos no cambió en los días siguientes: «Il dì medesimo fu ingazato uno che fu accusato di spionaggio, il quale andava con una cadena per torno, condutto da uno turco moro che glio fu mozza la testa; state 2 giorni vivo con gran suo patimento, alle fine morì, Iddio l'aiuta», p. 169. «Il dì medesimo fu impiccato 4 raise in presentia di tutta l'armata perchè fuggirono l'anno passato quando si combattette, et il bassà disse al figliolo di Rapomato, il quale fu lui il primo che fuggì l'anno passato, che se lui fugirà più lo farà impalare, lui lassò la sua bellissima galera alli schiavi che lo messero con la barca in terra. Questa giustitia fu fatta con arte in presentia di tutta l'armata, acciò che li altri paatroni di galea non fugissero se si combatterà questo anno, che Dio lo voglia se gli è per il meglio», p. 170. 
274 cañones pequeños, y de la bastarda de Ali Paşa 150.000 cequíes pasaron a las manos de la Santa Liga, 40.000 cequíes sacadas de otra nave ${ }^{35}$.

La necesidad urgente para una paz turco-veneciana era obvia. A pesar de la victoria, Felipe II rechazó las propuestas venecianas de destruir la armada otomana. Indudablemente, la destrucción total de las fuerzas navales de los turcos significaría la apropiación de las de la República. Y esto podría cambiar y dañar el equilibrio en las aguas mediterráneas. España estaba sumamente interesada en la conquista de Argel, Túnez y Trípoli, mientras Venecia soñaba con sus posesiones antiguas: Castelnovo, Valona y Durazzo ${ }^{36}$. Además de todo este desacuerdo, no se pudo lograr ningún acuerdo acerca de los futuros planes de guerra, sobre todo de Morea. Una fusión de intereses incompatibles, diversidad de políticas y oposición empezaron a llevar a la liga a una desintegración. Los aliados no pudieron decidir a dónde acudir? ¿Al norte de África o al Mediterráneo Oriental? Una desconfianza mutua y los celos entre los dos aliados, acompañados de su egoísmo irremediable trajeron el fin de la Santa Liga, cuya fundación Cervantes anotaba como «de felice recordación» ${ }^{37}$.

Pero irónicamente, el tratado firmado estaba a favor de los derrotados. En este tratado de paz que consistía en siete artículos, Venecia tuvo que consentir que Chipre se quedase como posesión otomana. El Sultán declaró casi sarcásticamente que el tributo que los venecianos antes pagaban a la Sublime Puerta por Chipre, es decir 8.000 ducados, no se pagaría más.

Aparte de Chipre, Sopoto en la costa albanesa se dejaría a los otomanos. Las minas de Kamengrad en Klis (Clissa) y otras dos fortalezas también se quedarían en la posesión otomana ${ }^{38}$. La República tuvo que retroceder a las fronteras que tenía antes de la guerra. Ambas partes devolvieron los bienes secuestrados a los mercaderes del partido contario. El impuesto tradicional que se pagaba por Zaklisa (Zante), 500.000 ducados, se triplicó. Con todo esto, el artículo más llamativo era

35. ARI, op. cit., p. 155.

36. FREIHERR VON PASTOR, op. cit., vol. XVIII, p. 396.

37. «A cabo de algún tiempo que llegué a Flandes, se tuvo nuevas de la liga que la Santidad del Papa Pío Quinto, de felice recordación, había hecho con Venecia y con España, contra el enemigo común, que es el Turco; el cual, en aquel mesmo tiempo, había ganado con su armada la famosa isla de Chipre, que estaba debajo del dominio de veneciano: y pérdida lamentable y desdichada»... «Súpose cierto que venía por general desta liga el serenísimo don Juan de Austria, hermano natural de nuestro buen rey don Felipe. Divulgóse el grandísimo aparato de guerra que se hacía. Todo lo cual me incitó y conmovió el ánimo y el deseo de verme en la jornada que se esperaba; y, aunque tenía barruntos, y casi promesas ciertas, de que en la primera ocasión que se ofreciese sería promovido a capitán, lo quise dejar todo y venirme, como me vine, a Italia. Y quiso mi buena suerte que el señor don Juan de Austria acababa de llegar a Génova, que pasaba a Nápoles a juntarse con la armada de Venecia, como después lo hizo en Mecina», Cervantes, M. de: Don Quijote de la Mancha, II, cap I.

38. UzunÇARșili, İ. H.: Osmanlı Tarihi, vol. III, parte I., TTK, Ankara, 1988, p. 25. 
que la República tenía que pagar 300.000 ducados -que se pagaría en tres años, 100.000 cada año- a la Puerta para recuperar los gastos de la guerra. Metaforicamente, era como ganar el pleito y tener que pagar los gastos del abogado de la parte contraria y las costas.

El Doge y el Senato, con una carta fechada 3 de abril de 1573 informaron a los embajadores venecianos en Madrid, Leonardo Donado y Lorenzo Priuli, de la paz que se acababa de firmar con la Sublime Puerta, y los embajadores oficialmente pasaron las noticias al Rey. La justificación era notable: Venecia había cumplido todas las responsabilidades que le correspondían; y las galeras y los soldados venecianos habían estado siempre alertas. Sin embargo, ahora que los turcos prepararon una nueva escuadra, las poblaciones de las costas dálmatas estaban inquietas y agotadas. Los venecianos estaban desesperados. Del mismo modo el país había sido militarmente y comercialmente debilitado ${ }^{39}$.

Es sorprendente que el Rey y el Papa recibieran las noticias de la paz recién acordada con la Puerta con asombro. Pero estas noticias no eran totalmente inesperadas para las dos partes. Una de las primeras cartas en las que encontramos la decepción que sufrió el Papa es la carta enviada a don Juan de Austria por don Juan de Zúñiga. En esta carta, enviada desde Roma a 7 de abril de 1573, podemos ver la reacción del Papa al respecto:

Anoche escriví a V. E. lo que me había embiado a decir el Cardenal de Coma de parte de su Santidad, y ahora vengo de Palacio y he hallado al Papa muy fatigado desta paz, pero con mucha flema para hacer la demostración que venecianos merecen. Preguntóme si tenía yo alguna orden de S. M. de lo que se había de hacer suscendiendo este caso, pues era cosa que siempre se había temido. Dixele que yo no la tenía ni creía que la tenía V. E., que era a quien se avía de dar, porque nunca se pensó que venecianos hicieran la paz sin aver dado primero cuenta a Su Santidad y a S. M. de que trataban della, y no aguardaran a concluirla al principio $[\ldots]^{40}$.

Las condiciones con que esta paz se ha hecho, no se han podido entender hasta agora, porque Su santidad dize que no las quiso escuchar. El embaxador de Venecia ha dicho a algunos que el turco les restituye todo lo que les había tomado en la Dalmacia, y que no se trata de Cipro. Ellos deben de aver hecho quanto el turco ha querido, y debían tener para esto larga comisión los ministros que tenían en Constantinopla. Donce dizen que se concluyó la paz a los VII de marzo ${ }^{41}$.

39. ARI, op. cit., p. 123.

40. Rosell, op. cit. p. 244.

41. Idem, p. 244. 
Don Juan de Austria, en su respuesta enviada a Don Juan de Zúñiga el 9 de abril del mismo año desde Nápoles, criticaba la actitud veneciana con un tono bastante severo y enfadado:

y si bien es verdad que ha muchos días que tenía antevisto lo que a sucedido, como me acuerdo haberlo scrito a VM., todavía me dio pena esta nueva, por ver la mala forma de proceder de aquellos hombres, y que con sus engaños ayan sido causa de que el Rey mi señor aya hecho muchos gastos que se pudieran excusar, por atender al bien univerdad y al partciular dellos ${ }^{42}$.

Por otra parte, el rey -prudente y sereno como siempre- recibió las noticias chocantes de la paz firmada entre la Puerta y la República sin ningún asombro. Dijo que si «Venecia creía obrar de aquel modo en favor de sus intereses, él había procedido siempre en bien de la Cristiandad y la República» ${ }^{43}$. Los embajadores venecianos que fueron a la corte española con la misión de informar al monarca católico que recientemente firmó la paz, ofrecieron un retrato muy vivo del sereno rey:

El Rey nos escuchó, siempre muy atentamente, y cuanto más observó la modestía indefectible de nuestro discurso cuando nos entramos en el argumento y nuestro discurso cogió una forma cariñosa de declamación que un asunto tan grave requerió, más de cerca nos miró, sosteniendo sus ojos fijos en nuestra dirección. No mostró ninguna emoción salvo cuando hacia el final (del discurso) se informó de que las condiciones de la paz habían sido aceptadas, se vio un ligero jesto irónico en sus labios. Sonrió ligeramente. Parecía que Su Majestad quiso decir, sin interrumpirnos, «Oh, lo habéis hecho, tal como me han dijeron que lo hariáis». Entonces, Su Majestad, en su modo habituado, no perturbado, llegando a un acuerdo con nosotros en modo que solía usar, respondió con estas pocas palabras: «Embajadores, ustedes nunca me han creado problemas. Ustedes han hecho bien en conseguir esta entrevista conmigo, pero yo era totalmente inconsciente de que me darían tales noticias, y como las acciones que se han llevado a cabo son sumamente importantes y requieren mucho pensamiento, no es apropiado que yo responda pronto. Debo considerar el asunto y enviaros una respuesta» ${ }^{44}$.

Felipe II no parecía decepcionado. No obstante, el Papa lo parecía. Estaba tan enfadado con los venecianos que en las cartas que despachó al rey y Don Juan de Austria les acusó de ser traidores y heréticos, y les amenazó con la excomunión. En el último paso, las profecías del nuncio papal Fachhinetti se cumplieron: Él

42. Idem, p. 245.

43. Idem, p. 148.

44. SetTon, K. M.: The Papacy and the Levant (1204-1571) vol IV: The Sixteenth Century from Julius III to Pius V, Filadelfia, 1984, p. 1094. 
tenía miedo de que «las negociaciones sobre la Liga se rompiesen totalmente, y los venecianos llegasen a acuerdo con los turcos» ${ }^{45}$.

Mientras tanto la derrota otomana incrementó en exceso los planes de sabotajes y conjuras. Una cantidad notable de los proyectos para incendiar las atarazanas de Constantinopla y el palacio de Topkapı fueron presentados a Felipe II por los griegos. No era ninguna simple coincidencia que la mayoría de estos proyectos fueran llevados a la corte española en los años 1572 y 1573 . Todos querían aprovecharse del caos que pensaban que reinaba en la capital otomana. Pero se equivocaban. El cardenal Mula era uno de los que se equivocaban. Había escrito con alegría que «los turcos no se podrán recuperar de este golpe y la flota cristiana era la dueña de los mares» ${ }^{46}$.

El triunfo era más simbólico que real. Los turcos reconstruyeron su armada en el invierno de 1571-72. Gracias a este periodo de indecisión y discrepancias en el bando cristiano, los otomanos pudieron reconstruir una nueva armada. Hacia los finales de junio la flota otomana compuesta de 150 galeras y comandada por Uluç Ali Baja (Occhiali) salió de Constantinopla.

En las vísperas de esta nueva campaña para restaurar la fama de la armada imperial, el Gran Visir Mehmet Sokullu, sumamente versado en el arte de la retórica, inmortalizó la pompa del imperio otomano con algunas palabras que citaremos aquí.

Cuando Kılıç Ali Paşa, un hombre más versado en el mundo militar que en el mundo de los asuntos estatales, comentó al Gran Visir Mehmet Sokullu la imposibilidad de una preparación rápida de algunas municiones, Sokullu pronunció estas palabras legendarias: «Señor Baja, el poder y los recursos de la Sublime Puerta son tan grandes que si se diera orden para que se proveyesen anclas de plata, aparejos de seda y velas de raso, sería posible. Cualquier cosa que falte, solo pídemelo» ${ }^{47}$.

Después de la paz turco-veneciana Constantinopla se convirtió en un hervidero de diplomáticos. El día 18 de julio vinieron los españoles a la corte turca, y solo un mes después, el 12 de agosto de 1574 , los alemanes renovaron sus tratados. Mucho después, en julio el bailo Barbaro informó el Doge Mocenigo de la salida de 240 galeras rumbo a Berbería. El comendador de la flota era Ali Pasa (Ochali) que reconquistó Túnez en menos de seis meses después de la conquista de la ciudad por Juan de Austria. Cuatro meses después de Lepanto, Jacopo Soranzo fue enviado a Murad III como embajador para celebrar su ascensión al trono. Once años después de la batalla naval, Soranzo volvió a la capital turca con el mismo título diplomático, esta vez para asistir a la fiesta de circuncisión del hijo

45. Freiherr von PAStor, op. cit., vol. XVIII, p. 426.

46. Idem, p. 426.

47. SETTON, op. cit., p. 1075. 
del mismo sultán: Murad III. Como otras fiestas y bodas pomposas de los infantes, infantas y los oficiales de alto rango del estado, esta era solo un medio para hacer ostentación de riquezas y poder.

Es verdad que se escribió mucho en conmemoración de Lepanto para inmortalizar la victoria. Pero también contamos con un extenso corpus de obras con las que se satirizó la actitud veneciana después de la batalla. Los españoles que nunca dejaron de criticar a la República por ser los aliados de «los turcos infieles», considerando sus provechos, no perdieron ninguna oportunidad de usar Lepanto para mofarse de los venecianos. Francifredo, dux de Venecia (melodrama tétricoterrorifico en dos actos) de Mariano de Pina y Bohigas es uno de los ejemplos llamativos de este corpus. Todas las características del mundo veneciano -buenas o malas- parecían haber sido utilizadas para crear una imagen paradójica de la República. La escena teatral es la ciudad de los canales en 1571. Así, el autor no pierde la oportunidad de atacar a los turcos e insultarles mientras tanto.

El primer acto se abre con una escena alegre en el palacio ducal en Venecia. Por supuesto, ninguna escena podría haber servido mejor que la de la época de carnavales. Todo está representado alegóricamente en un estilo carnavalesco. Aunque el tema tiene poco que ver con Lepanto, el autor inserta una imagen degradante del sultán turco, Selim II:

Fiorina.- ¡ Viva el carnaval y viva el placer!

Todos.- ¡Viva!

Astolfo.- Venecia con sus torres de diamantes, con sus canales de plata, con sus góndolas de marfil y sus músicas y sus cantos, parece un flotante paraíso, sobre un mar de ventura y felicidad. Y el carnaval durará este año ocho días más, por acuerdo del muy poderoso Tribunal de los Diez, de que formo parte, (Todos se descubren la cabeza.) si como se espera, llega la noticia de que nuestra poderosa escuadra ha vencido a Selim.

Fiorina.- ¿Quién es Selim? ¿Algún perro?

Astolfo.- $¡$ Y perro de presa! Selim es el Gran Turco.

Fiorina.- Ya, el turco mayor.

Astolfo.- Justo, el rey de los turcos, que echándola de matón, y queriendo cobrar el barato en nuestros mares, se atreve a desafiar a toda la cristiandad.

Todos.- ¡Qué barbaridad!

Fiorina.- ¿Por supuesto le zurrarán de firme?

Astolfo.- De eso se trata, y con tal fin han armado escuadras todas las naciones cristianas, y Venecia ha visto salir del Adriático sesenta buques con cuatro mil cañones, al mando de su ilustre Dux el invicto general Francifredo, que a estas horas volverá a su patria cargado de laureles.

Fiorina.- ¿Invicto general?... ¿Qué campañas ha hecho? 
Astolfo.- Ninguna. Por eso es invicto, y por eso ha llegado al primer puesto del Estado y de la milicia. En nuestro país hacemos las cosas de ese modo. Por lo tanto, preparémonos a recibir al insigne caudillo, y a demostrarle nuestro entusiasmo y alegría, con bailes, regatas y fuegos de artificio.

Fiorina.- ¡Viva el Dux!

Todos.- ¡Viva!» ${ }^{48}$.

En toda la trama, el Doge es satirizado creando una figura cómica alrededor del propio Doge, a la que se atribuyen todas las características que un príncipe no debería tener: cobarde, mentiroso, dedicado a los placeres terrestres, obsesivo.

Del mismo modo, Francisco de Quevedo, el genio español del Siglo de Oro mostró una habilidad literaria sorprendente en el mundo de las sátiras. En su obra Sueños y discursos de verdades descubridoras de abusos, vicios y engaños en todos los oficios y estados del mundo, la cual manifiesta el mismo antagonismo hacia Venecia y los venecianos. Sin duda, después de la desintegración de la Santa Liga, la elite intelectual de la sociedad española no dejó de mostrar hostilidad hacia Venecia a través de obras literarias. Y Quevedo no era ninguna excepción. A través de la boca de un nigromante, nuestro ilustre autor critica los ciudadanos de la República:

- ¿Si la hay? - dije yo-. No hay otra cosa sino Venecia y venecianos.

- ¡Oh, doyla al diablo - dijo el nigromántico - por vengarme del mismo diablo, que no sé que pueda darla a nadie sino por hacerle mal. Es república esa que mientras que no tuviere conciencia durará, porque si restituye lo ajeno no les queda nada. Linda gente, la ciudad fundada en el agua, el tesoro y la libertad en el aire, y la deshonestidad en el fuego, y al fin es gente de quien huyó la tierra, y son narices de las naciones y el albañar de las monarquías, por donde purgan las inmundicias de la paz y de la guerra, y el turco los permite por hacer mal a los cristianos y los cristianos por hacer mal a los turcos, y ellos, por poder hacer mal a unos y a otros, no son moros ni cristianos, y así dijo uno de ellos mismos, en una ocasión de guerra, para animar a los suyos contra los cristianos: « $i \mathrm{Ea}$, que antes fuisteis venecianos que cristianos!». Dejemos eso y dime, ¿hay muchos golosos de valimientos de los señores del mundo?

Como el Gran Visir, Sokullu Mehmet Paşa comentó con gran soberbia, los otomanos con la toma de Chipre les cortaron el brazo a los venecianos, mientras los venecianos con la batalla de Lepanto afeitaron la barba a los otomanos. Paşa, seguía con su discurso metafórico, en el estilo clásico de la corte otomana: el brazo amputado no volvería a crecer, pero la barba afeitada crecería más fuerte

48. De Pina y Bohigas, M.: Francifredo, dux de Venecia: melodrama tétrico-terrorífico en dos actos, Biblioteca Virtual Miguel de Cervantes, 2002. 
que antes. Y tenía razón: la barba no tardó nada en crecer, como un dragón con siete cabezas, pero el brazo amputado no volvió a desarrollarse.

Así empezó una nueva época de la fricción entre los otomanos y los Habsburgo. Lo toma de Túnez por Don Juan de Austria el 11 de octubre de 1573 siguió con su recuperación por los turcos el 13 de septiembre de 1574, más la conquista de La Goleta, el 25 de agosto del mismo año. Era la mejor demostración de cómo las fuerzas navales otomanas habían recuperado su antiguo poder en poco tiempo. «Perdióse, en fin, la Goleta; perdióse el fuerte, sobre las cuales plazas hubo de soldados turcos, pagados, setenta y cinco mil, y de moros, y alárabes de toda la África, más de cuatrocientos mil, acompañado este tan gran número de gente con tantas municiones y pertrechos de guerra, y con tantos gastadores, que con las manos y a puñados de tierra pudieran cubrir la Goleta y el fuerte», así comentaría Cervantes a través de la boca de su «narrador». El maestro de la pluma, busca una buenísima excusa para su perdición y no duda de exponerla: «Pero a muchos les pareció, y así me pareció a mí, que fue particular gracia y merced que el cielo hizo a España en permitir que se asolase aquella oficina y capa de maldades, y aquella gomia o esponja y polilla de la infinidad de dineros que allí sin provecho se gastaban, sin servir de otra cosa que de conservar la memoria de haberla ganado la felicísima del invictísimo Carlos Quinto; como si fuera menester para hacerla eterna, como lo es y será, que aquellas piedras la sustentaran».

Las guerras, fricciones y confrontaciones en esta zona del norte de África se convirtieron en un círculo vicioso. Lo que permaneció fijo e inmutable fue el mito creado por la batalla de Lepanto y la derrota de los turcos. De una forma u otra, los autores no dejaron de referirse a este hecho victorioso en el mundo de literatura. Todo esto sirvió como un tema cotidiano y coloquial para la gente modesta de la calle, en las «plazas mediterráneas». Las palabras de Pablos de La vida del Buscón, el famoso protagonista de Francisco de Quevedo, muestra perfectamente cómo el mito sufrió una metamorfosis, pasando de una boca a la otra, y por otro lado el turco empezó a dejar de ser un «ogro» en el ámbito ibérico.

Llegó la noche oscura y acogímonos a casa todos. Entré y hallé al soldado de los trapos con una hacha de cera que le dieron para acompañar un difunto y se vino con ella. Llamábase éste Magazo, natural de Olías; había sido capitán en una comedia y combatido con moros en una danza. A los de Flandes decía que había estado en la China, y a los de la China en Flandes. Trataba de formar un campo y nunca supo sino espulgarse en él. Nombraba castillos y apenas los había visto en los ochavos. Celebraba mucho la memoria del señor don Juan, y oíle decir yo muchas veces de Luis Quijada que había sido honra de amigos. Nombraba turcos, galeones y capitanes, todos los que había leído en unas coplas que andaban de esto; y como él no sabía nada de mar, porque no tenía de naval más del comer nabos, dijo, contando la batalla que había vencido el señor don Juan en Lepanto, que aquel Lepanto fue 
un moro muy bravo, como no sabía el pobrete que era nombre del mar. Pasábamos con él lindos ratos ${ }^{49}$.

\section{Bibliografía}

Ari, B.: «Las últimas fases de la lucha por el dominio del Mediterráneo entre dos superpotencias; el Imperio Otomano y la Monarquía Hispana», en ed. Martín Asuero, P.; YaycioĞlu, M.; Toledo. Cervantes y el Mediterráneo Hispano-Otomano, Estambul, 2006.

ArI, B.: «Battaglia di Lepanto descritta da Gerolamo Diedo, Biblioteca Rara. Misc. Vol I. Bertelè, T.: Il palazzo degli ambasciatori de Venezia a Costantinapoli e le sue antiche memorie. Bolonia, 1932.

FENLON, I.: «Lepanto and the arts of celebration in Renaissance Venice», Proceedings of the British Academy, 73, 1987.

Freiherr von Pastor, L.: History of the Popes, ed. Kerr, R. F. vol. XVIII. London, 1952.

İNALCIK, H.: «El imperio otomano y España en el Mediterráneo (1551-1571). Lepanto en los documentos otomanos», en ed. Martín Asuero, P.; YaycioĞlu, M.; Toledo. Cervantes y el Mediterráneo hispano-otomano, Estambul, 2006.

LAMANsky, V.: Secrets d'etat de venise:Documents extraits notices et etudes, vol. I. Nueva York, 1968.

Pallucchini, A.: «Echi della battaglia di lepanto nella pittura Veneziana del '500», en ed. Benzoni, G. Il mediterraneo nella seconda metà del '500 alla luce di Lepanto.

Paruta, P.: Historia dell Guerra di Cipro. Venecia, 1615.

Pia Pedani-Fabris (ed.): Relazioni di ambasciatori veneti al Senato, vol. XIV, ed. M. PADUA, 1996.

Pina y Bohigas, M. de: Francifredo, dux de Venecia : melodrama tétrico-terrorifico en dos actos, Biblioteca Virtual Miguel de Cervantes.

Preto, P.: Venezia e i turchi. Florencia, 1975.

Rosell, C.: Historia del combata naval de Lepanto, Madrid, 1853.

SetTon, K. M.: The Papacy and the Levant (1204-1571) vol IV: The Sixteenth Century from Julius III to Pius V, Filadelfia, 1984.

SolA, E.: Los que van y vienen: Información y fronteras en el Mediterráneo del siglo XVI. Alcalá de Henares, 2005.

UzunçArşılı, İ. H.: Osmanlı Taribi, vol. III, parte I., TTK, Ankara, 1988.

49. Quevedo, F. de: La vida del Buscón, libro III, cap. II. 